\title{
Analisis Boraks pada Jajanan Bakso di Kota Jambi
}

\section{Borax Analysis on Meatball Snacks in Jambi}

Sri Gustini*, Yulianis, Deny Sutrisno

Program Studi Farmasi, Sekolah Tinggi Ilmu Kesehatan Harapan Ibu, Jambi, Indonesia

*Corresponding author: srigustini914@gmail.com

Submitted: 5 Oktober 2020

Accepted: 12 Desember 2020

Published: 29 Agustus 2021

\begin{abstract}
Introduction: Food additives is difficult to avoid as they evolve with the times. Based on the Indonesian Minister of Health Regulation No. 33/2012, a chemical compound is known as borax is stated to be a substance that is prohibited from being used in food manufacturing. Meatball is a snack favored by the community. Objective: This study aimed to screen the borax content using tumeric paper and a UV-Vis spectrophotometer at meatball snacks in Jambi City. Methods: The types of meatballs taken as samples were stick meatballs, grilled meatballs, and soup meatballs. Each meatball sample is taken from a seller in Jambi City. Results: Based on research conducted on samples of meatball soup ( $k$ ), grilled meatball $(b)$ and meatball stick $(t)$, there were 53 samples from Jambi City. Of the 53 samples analyzed, there was 1 sample containing borax with the code Ft3. Conclusion: This study shows that 1 of 53 meatball samples with code Ft3 had borax approximately 0,058\%.
\end{abstract}

Keywords: borax, meatball snacks, uv-vis spectrophotometer, tumeric paper

\begin{abstract}
Abstrak
Pendahuluan: Seiring dengan perkembangam zaman, penambahan bahan tambahan pangan sulit untuk dihindari. Berdasarkan PERMENKES RI No 33 Tahun 2012 salah satu senyawa kimia yang dikenal dengan nama boraks dinyatakan bahan yang dilarang digunakan dalam pembuatan makanan. Bakso merupakan jajanan yang digemari oleh masyarakat. Tujuan: Penelitian ini bertujuan skrining kandungan boraks menggunakan kertas tumerik dan kadar boraks dengan spektrofotometer UV-Vis pada jajanan bakso di Kota Jambi. Metode: Jenis bakso yang diambil sebagai sampel adalah bakso tusuk, bakso bakar dan bakso kuah. Setiap sampel bakso dilakukan uji dari penjual di Kota Jambi. Hasil: Berdasarkan penelitian yang di lakukan pada sampel bakso kuah (k), bakso bakar (b) dan bakso tusuk (t) terdapat 53 sampel yang berasal dari Kota Jambi. Dari ke 53 sampel yang di analisis terdapat 1 sampel yang mengandung boraks dengan kode Ft3. Kesimpulan: Penelitian ini menunjukan bahwa 1 dari 53 sampel bakso yang dilakukan analisis dengan kertas tumerik terdapat 1 sampel dengan kode Ft3 yang terdeteksi mengandung boraks. Kadar boraks dalam sampel Ft3 sebesar 0,058\%.
\end{abstract}

Kata kunci: boraks, jajanan bakso, kertas tumerik, spektrofotometer uv-vis

\section{PENDAHULUAN}

Keamanan pangan merupakan salah satu masalah yang harus mendapatkan perhatian terutama di negara berkembang seperti Indonesia, karena bisa berdampak buruk terhadap kesehatan termasuk bahan pangan. Fungsi bahan tambahan pangan khususnya bahan pengawet menjadi semakin penting. Sejalan dengan kemajuan zaman banyak bahan tambahan pangan dalam harga yang relatif murah akan mendorong peningkatan pemakain tambahan pangan yang murah (Triastuti dkk., 2013).

Saat ini, industri pangan di Indonesia telah berkembang sangat pesat, ditandai dengan banyaknya industri kecil maupun besar memproduksi berbagai macam makanan, sehingga banyak pedagang menggunakan bahan-bahan adiktif yang relatif murah 
seperti boraks. Boraks merupakan senyawa kimia berbahaya untuk pangan dengan nama kimia natrium tetrabonat (Binus University, 2016). Boraks dapat mengakibatkan berbagai penyakit seperti gangguan pada janin, gangguan proses reproduksi, menimbulkan iritasi pada lambung dan menyebabkan gangguan pada ginjal, hati dan testis (Fitri dkk., 2018). Konsumsi makanan yang memiliki kandungan boraks dapat berdampak pada kesehatan seperti pusing, mual, muntah mencret dan dapat mengakibatkan kerusakan ginjal bahkan kematian (Kresnadipayana \& Dwi, 2017).

Di Kota jambi boraks dikenal dengan nama bleng atau pijer yang disalahgunakan sebagai bahan tambahan pangan yang bertujuan untuk pengenyal ataupun sebagai pengawet. Bakso adalah jenis makanan bulat yang terbuat dari tepung, daging, ayam dl. Kota Jambi terdiri dari 11 Kecamatan yaitu Kecamatan Pelayangan, Danau Teluk, Telanaipura, Danau Sipin, Kota Baru, Paal Merah, Jambi Selatan, Jambi Timur, Alam Barajo, Pasar Jambi dan Jelutung. Tujuan penelitian ini yaitu "menganalisis kandungan dan kadar boraks dengan spektrofotometer UV- Vis pada jajanan bakso di Kota Jambi".

\section{BAHAN DAN METODE}

Penelitian ini menggunakan metode penelitian eksperimental yaitu mengetahui adanya kandungan boraks dalam jajanan bakso kuah, bakso bakar dan bakso tusuk di Kota Jambi. Masing - masing sampel di ambil dari pedagang bakso di kota jambi secara puposive sampling.

\section{Alat dan bahan}

Alat yang digunakan dalam penelitian ini yaitu Spektrofotometer UV-Vis (Shimadzu-1800), Batang Pengaduk (pyrex), Labu Erlenmeyer 100 mL (pyrex), Gelas piala, Gelas ukur, Labu ukur, Lumpang, Alu, Kertas saring, Pipet ukur $5 \mathrm{~mL}$, Sentrifus (Hettich), Vial $10 \mathrm{~mL}$, Bunsen, Kaki tiga, Penangas air (waterbath), Drying oven, Cawan penguap dan Kertas tumerik. Bahan yang di pakai pada penelitian ini adalah sampel bakso kuah, bakso bakar, bakso tusuk yang di peroleh dari pedagang yang berjualan di Kota Jambi, alkohol $70 \%$ (pa), air suling, kunyit, asam sulfat pekat (pa), asam asetat glasial (pa), etanol 96\% (pa), kurkumin 0,125\%, dan serbuk boraks.

\section{Prosedur kerja}

\section{Pengambilan sampel}

Sampel di ambil dari pedagang di Kota Jambi yang terdapat jajanan bakso seperti sampel bakso kuah (k), bakso bakar (b) dan bakso tusuk (t). terdapat 53 sampel yang berasal dari kota jambi secara purposive sampling dengan jumlah sampel yang berbeda-beda disetiap tempat yaitu 2 sampel dari Pelayangan, 2 sampel dari Danau Teluk, 5 sampel dari Telanaipura, 5 sampel dari Danau Sipin, 6 sampel dari Kota Baru, 8 sampel dari Paal Merah, 6 sampel dari Jambi Selatan, 5 sampel dari Alam Barajo, 6 sampel dari Jambi Timur, 4 sampel dari Pasar Jambi dan 4 sampel dari Jelutung.

Lima puluh tiga sampel bakso yang terdiri dari 39 bakso kuah (k), 10 bakso bakar (b) dan 4 bakso tusuk (t) telah di analisis dari kota jambi. Sampel di pilih berdasarkan ciri - ciri bakso yang mengandung boraks. Tiap sampel di beri kode A,B,C,D,E,F,G,H,I,J,K sampel A dari Pelayangan, sampel B dari Danau Teluk, sampel C dari Telanaipura, sampel D dari Danau Sipin, sampel E dari Kota Baru, sampel F dari Paal Merah, sampel G dari Jambi Selatan, sampel H dari Alam Barajo, sampel I dari Jambi Timur, sampel J dari Pasar Jambi dan sampel K dari Jelutung.

Tiap sampel yang di ambil dilakukan uji kualitatif menggunakan kertas tumerik. Sampel yang positif mengandung boraks di uji kuantitatif menggunakan spektrofotometer UV-Vis.

\section{Pembuatan pereaksi pendeteksi boraks menggunakan kertas tumerik}

Proses pembuatan pereaksi boraks ini diawali dengan mengupas kunyit sebanyak $100 \mathrm{~g}$ lalu dicuci dan diparut. Lalu air kunyit disaring dengan kertas saring. Air kunyit yang di dapatkan lalu di tampung dan diukur menggunakan gelas ukur. Kemudian tambahkan sebanyak $5 \mathrm{ml}$ alkohol $70 \%$ ke dalam $50 \mathrm{ml}$ air kunyit yang di dapatkan. Mengambil kertas saring, gunting persegi ukuran $8 \times 8 \mathrm{~cm}$ dan mencelupkan kedalam air kunyit, bolak baliklah menggunakan pinset sampai merata pada seluruh permukaan kertas saring. Kertas di letakkan pada loyang dan di angin -anginkan agar kering, setelah kering kertas yang berukuran $8 \times 8 \mathrm{~cm}$ di potong menjadi ukuran $1 \mathrm{~cm}$ (Hartati, 2017).

\section{Analisis boraks secara kualitatif dengan kertas tumerik}

Sampel ditimbang sebanyak $1 \mathrm{~g}$ lalu di tambahkan aqua dest 1:10. Campuran ini lalu di haluskan dengan lumpang dan disaring menggunakan kertas saring. Cairan yang telah di saring di tempatkan dalam gelas piala. Celupkan kertas tumerik yang telah di siapkan ke dalam cairan sampel selama 1 - 2 menit. Uji positif ditandai dengan perubahan warna na dari kuning menjadi merah kecoklatan maka dapat disimpulkan bahwa sampel positif mengandung boraks (Hartati, 2017). 


\section{Pembuatan supernatan dari bakso}

Sampel bakso diperalkukan semua sama yaitu dengan di timbang $5 \mathrm{~g}$ lalu di tambahkan dengan $10 \mathrm{~mL}$ aqua dest. Sampel di gerus atau di halus dengan lumpang. Setelah di haluskan, sampel dimasukan ke dalam tabung sentry fusa. Proses sentrifugasi dilakukan selama kurang lebih 2 menit dengan menggunakan kecepatan 3000 rpm. Bagian super nata kemudian di ambil dengan cara di saring dengan kertas saring dan di cuci lagi dengan aqua dest. Supernatan yang di dapatkan di tambahkan dengan aqua dest sampai dengan $25 \mathrm{ml}$. Larutan supernatan tersebut akan digunakan untuk analisis boraks secara kuantitatif dengan spektrofotometer UV-Vis (Pane, 2012).

\section{Penentuan kadar boraks}

Analisis panjang gelombang maksimum dan pembuatan kurva standar boraks.

Timbang $10 \mathrm{mg}$ serbuk boraks dan dilarutkan dengan aqua dest sampai dengan $100 \mathrm{~mL}$ di labu ukur sehingga konsentrasi larutan $100 \mu \mathrm{g} / \mathrm{mL}$. Encerkan menjadi konsentrasi sebesar 2,5 $\mu \mathrm{g} / \mathrm{mL}, 5 \mu \mathrm{g} / \mathrm{mL}$, $10 \mu \mathrm{g} / \mathrm{mL}, 20 \mu \mathrm{g} / \mathrm{mL}, 30 \mu \mathrm{g} / \mathrm{mL}$ dengan cara larutan induk di pipet sebesar 0,25 mL, 0,5 mL, $1 \mathrm{~mL}, 2 \mathrm{~mL}$ dan $3 \mathrm{~mL}$.

Dari larutan induk yang telah dipipet masingmasing larutan di masukan kedalam cawan porselin. Kemudian 2 mL larutan $\mathrm{NaOH}$ 10\% ditambahkan pada larutan standar kemudian di panaskan diatas penangas air sampai larutan kering. Pemanasan di lanjutkan dengan oven pada suhu $50^{\circ} \mathrm{C}$ selama 5 menit. Ditambahkan larutan air kunyit $0,125 \%$ sebanyak $2 \mathrm{~mL}$ lalu dipanaskan sambil di aduk selama 2 menit. Setelah larutan dingin di tambahkan $2 \mathrm{~mL}$ larutan asam sulfat dan $2 \mathrm{~mL}$ asam asetat. Aduk larutan sampai tidak ada warna kuning dan diamkan selama 8 menit, lalu larutan ditambahkan sedikit etanol. Kemudian disaring larutan dengan kertas saring lalu dimasukan kedalam labu ukur $10 \mathrm{ml}$ dan encerkan dengan etanol $96 \%$ sampai garis tanda.

Untuk penentuan panjang gelombang maksimum digunakan larutan standar boraks $20 \mu \mathrm{g} / \mathrm{ml}$ dari boraks murni. Larutan ini diamati serapannya pada panjang gelombang antara $400-600 \mathrm{~nm}$ pada alat spektrofotometer UV-Vis (Pane, 2012). Dalam penentuan kurva standar dengan mengukur nilai serapan larutan standar yang telah diperoleh panjang gelombang maksimum.

\section{Penentuan kadar boraks pada sampel bakso menggunakan spektrofotometer UV-Vis}

Larutan supernatan yang telah disiapkan dipipet sebanyak $1 \mathrm{~mL}$ lalu di tambahkan dengan $\mathrm{NaOH} 10 \%$ sebanyak $2 \mathrm{~mL}$ dalam cawan porselin. Panaskan cawan tersebut sampai larutan kering. Pemanasan dilanjutkan dengan oven pada suhu $50^{\circ} \mathrm{C}$ selama 5 menit. Setelah kering tambahkan larutan air kunyit dan dipanaskan sambil di aduk selama 2 menit lalu dinginkan. Setelah dingin, tambahkan $2 \mathrm{~mL}$ larutan asam sulfat dan $2 \mathrm{~mL}$ asam asetat kemudian aduk larutan sampai kuningnya hilang. Diamkan larutan tersebut selama 8 menit dan tambahkan sedikit etanol dan disaring dengan penyaring. masukkan kedalam labu ukur $10 \mathrm{~mL}$ dan encerkan dengan etanol $96 \%$ sampai garis tanda. Hasil saringan tersebut di kumpulkan dan di tentukan panjang gelombang maksimum lalu diamati serapannya pada panjang gelombang maksimum dengan menggunakan blanko etanol 96\%, blanko tersebut tidak menggunakan overlay antara lartan standar dengan lartan sampel.

\section{HASIL DAN PEMBAHASAN}

Berdasarkan penelitian yang di lakukan pada sampel bakso kuah (k), bakso bakar (b) dan bakso tusuk (t) terdapat 53 sampel yang berasal dari Kota Jambi. Dari ke 53 sampel yang di analisis terdapat 1 sampel yang mengandung boraks dengan kode $\mathrm{Ft} 3$.

Uji kualitatif pada penelitian ini menggunakan kertas tumerik. Kertas tumerik adalah kertas yang terbuat dari kertas saring yang di celupkan ke dalam ekstrak kunyit. Kertas tumerik yang telah dibuat dilakukan uji kesetabilannya mendeteksi boraks dalam waktu 21 hari dalam larutan boraks. Pada hari ke 6 - 21 mengalami penurun yang di tandai dengan warna merah kecoklatan yang memudar. Kertas tersebut stabil dalam 5 hari. Jika sampel positif mengandung boraks maka warna akan berubah dari kuning menjadi merah kecoklatan (Suseno, 2019). Penambahan boraks dalam makanan khususnya bakso merupakan suatu pelanggaran dalam proses produksi makanan olahan.

Hasil penelitian ini menunjukan bahwa 53 sampel bakso yang di uji dengan kertas tumerik terdapat 52 sampel yang tidak mengalami perubahan warna (negatif) dan 1 sampel yang mengalami perubahan warna dari kuning berubah menjadi warna merah kecoklatan seperti tertera pada Tabel 1. Konsentrasi sampel di peroleh 11,76 ug/mL, boraks dalam makanan tidak boleh sama sekali dikondumsi (Kresnadipayana \& Dwi, 2017). Konsentrasi kurkumin itu berdasarkan jurnal org lain. Kurkumin dapat menguraikan ikatanikatan boraks (Na2.B4.O7.10H2O) menjadi asam borat $\left(\mathrm{H}_{3} \mathrm{BO}_{3}\right)$ yang akan mengikat warna (merah kecoklatan) yang di sebut dengan senyawa boron cyano kurkumin kompleks atau kelat rosasianin (Widelia dkk., 2018). 
Tabel 1. Hasil uji boraks dengan kertas tumerik

\begin{tabular}{|c|c|c|c|c|}
\hline No. & Sampel & Sebelum Pengujian & Setelah Pengujian & Hasil \\
\hline 1. & Sampel At1 & Kuning & Kuning & Negatif (-) \\
\hline 2. & Sampel Ak1 & Kuning & Kuning & Negatif (-) \\
\hline 3 & Sampel Bb1 & Kuning & Kuning & Negatif (-) \\
\hline 4 & Sampel Bk2 & Kuning & Kuning & Negatif (-) \\
\hline 5 & Sampel Cb2 & Kuning & Kuning & Negatif (-) \\
\hline 6 & Sampel Ck3 & Kuning & Kuning & Negatif (-) \\
\hline 7 & Sampel Ck4 & Kuning & Kuning & Negatif (-) \\
\hline 8 & Sampel Ck5 & Kuning & Kuning & Negatif (-) \\
\hline 9 & Sampel Ck6 & Kuning & Kuning & Negatif (-) \\
\hline 10 & Sampel Db3 & Kuning & Kuning & Negatif (-) \\
\hline 11 & Sampel Dk7 & Kuning & Kuning & Negatif (-) \\
\hline 12 & Sampel Dk8 & Kuning & Kuning & Negatif (-) \\
\hline 13 & Sampel Dk9 & Kuning & Kuning & Negatif (-) \\
\hline 14 & Sampel Dk10 & Kuning & Kuning & Negatif (-) \\
\hline 15 & Sampel Eb4 & Kuning & Kuning & Negatif (-) \\
\hline 16 & Sampel Et2 & Kuning & Kuning & Negatif (-) \\
\hline 17 & Sampel Eb5 & Kuning & Kuning & Negatif (-) \\
\hline 18 & Sampel Eb6 & Kuning & Kuning & Negatif (-) \\
\hline 29 & Sampel Ek11 & Kuning & Kuning & Negatif (-) \\
\hline 20 & Sampel Ek12 & Kuning & Kuning & Negatif (-) \\
\hline 21 & Sampel Fb7 & Kuning & Kuning & Negatif (-) \\
\hline 22 & Sampel Fb8 & Kuning & Kuning & Negatif (-) \\
\hline 23 & Sampel Fk13 & Kuning & Kuning & Negatif (-) \\
\hline 24 & Sampel Ft3 & Kuning & Merah kecoklatan & Positif (+) \\
\hline 25 & Sampel Fk14 & Kuning & Kuning & Negatif (-) \\
\hline 25 & Sampel Fk15 & Kuning & Kuning & Negatif (-) \\
\hline 27 & Sampel Fk16 & Kuning & Kuning & Negatif (-) \\
\hline 28 & Sampel Fk17 & Kuning & Kuning & Negatif (-) \\
\hline 29 & Sampel Gb9 & Kuning & Kuning & Negatif (-) \\
\hline 30 & Sampel Gk18 & Kuning & Kuning & Negatif (-) \\
\hline 31 & Sampel Gk19 & Kuning & Kuning & Negatif (-) \\
\hline 32 & Sampel Gk20 & Kuning & Kuning & Negatif (-) \\
\hline 33 & Sampel Gk21 & Kuning & Kuning & Negatif (-) \\
\hline 34 & Sampel Gk22 & Kuning & Kuning & Negatif (-) \\
\hline 35 & Sampel Hb10 & Kuning & Kuning & Negatif (-) \\
\hline 36 & Sampel Hk23 & Kuning & Kuning & Negatif (-) \\
\hline 37 & Sampel Hk24 & Kuning & Kuning & Negatif (-) \\
\hline 38 & Sampel Hk25 & Kuning & Kuning & Negatif (-) \\
\hline 49 & Sampel Hk26 & Kuning & Kuning & Negatif (-) \\
\hline 40 & Sampel It4 & Kuning & Kuning & Negatif (-) \\
\hline 41 & Sampel Ik27 & Kuning & Kuning & Negatif (-) \\
\hline 42 & Sampel Ik28 & Kuning & Kuning & Negatif (-) \\
\hline 43 & Sampel Ik29 & Kuning & Kuning & Negatif (-) \\
\hline 44 & Sampel Ik30 & Kuning & Kuning & Negatif (-) \\
\hline 45 & Sampel Ik31 & Kuning & Kuning & Negatif (-) \\
\hline 46 & Sampel Jk32 & Kuning & Kuning & Negatif (-) \\
\hline 47 & Sampel Jk33 & Kuning & Kuning & Negatif (-) \\
\hline 48 & Sampel Jk34 & Kuning & Kuning & Negatif (-) \\
\hline 49 & Sampel Jk35 & Kuning & Kuning & Negatif (-) \\
\hline 50 & Sampel Kk36 & Kuning & Kuning & Negatif (-) \\
\hline 51 & Sampel Kk37 & Kuning & Kuning & Negatif (-) \\
\hline 52 & Sampel Kk38 & Kuning & Kuning & Negatif (-) \\
\hline 53 & Sampel Kk39 & Kuning & Kuning & Negatif (-) \\
\hline
\end{tabular}

Berdasarkan analisis pada penelitian ini sampel Ft3 yang memiliki kandungan boraks mempunyai tekstur yang lebih kenyal, cenderung agak putih dan penyimpanan lebih tahan lama. Pada penelitian lainnya diperoleh panjang gelombang max boraks $428 \mathrm{~nm}$ sedangkan pada penelitian ini panjang gelombang max 
yang di dapat adalah 422,50 nm (Kresnadipayana \& Dwi, 2017). Perbedaan panjang gelombang maksimum ini di sebabkan karena preparasi sampel yang berbeda karena proses penyiapan sampel yang berbeda mempengaruhi panjang gelombang sehingga tercipta panjang gelombang yang berbeda tertera pada Tabel 2 dan hasil pengukuran serapan seri konsentrasi larutan standar boraks pada Gambar 1.

Tabel 2. Hasil dari uji kertas tumerik pada sampel bakso

\begin{tabular}{ccccc}
\hline No & Sampel & Hasil & Sebelum Uji & Setelah Uji \\
\hline 1 & Sampel Fk13 & Negatif (-) & & \\
\hline & & & & \\
\hline & Sampel Ft3 & Positif (+) & & \\
& & & & \\
\hline
\end{tabular}

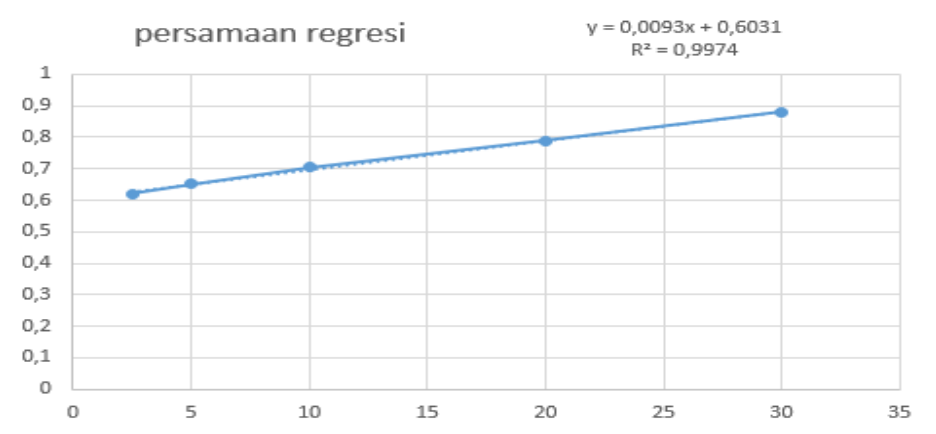

Gambar 1. Kurva standar boraks; y (persamaan regresi), $\mathrm{R}^{2}$ (koefisien determinasi)

Pada penelitian ini didapatkan nilai koefisien korelasi $\left(\mathrm{R}^{2}\right)$ yaitu 0,9974 Nilai koefisien korelasi yang telah di peroleh merupakan hubungan antara konsentrasi larutan standar boraks dengan absorbansinya yaitu telah memenuhi kriteria (parameter) linier. Nilai range linier yang di peroleh bahwa kurva kalibrasi tersebut berlaku hukum lambert-beer (Sayuthi \& Puji, 2017). Pengujian boraks pada sampel di dapatkan panjang gelombang 422,50 nm Dengan nilai rata-rata absorbansi 0,712483 dengan pengulangan sebanyak tiga kali. Hasil pengukuran absorban menunjukan bahwa semakin besar konsentrasi makan semakin besar pula absorban yang di peroleh (Sayuthi \& Puji, 2017).

Pemeriksaan kandungan boraks pada bakso Ft3 awalnya menggunakan uji kualitatif menggunakan kertas tumerik dan uji kuantitatif yaitu spektrofotometer UV-Vis. Langkah pertama dilakukan pengujian sampel dengan kertas tumerik dimana kertas tumerik ini mengandung senyawa kurkumin yang berfungsi untuk membentuk kompleks boron dan reaksi atau molekul komplek yang terbentuk (Silalahi dkk., 2010; Triastuti dkk. 2013. Nurkholidah \& Jose, 2012). Selanjutnya di lakukan uji kuantitatif dengan spektrofotometri UV-Vis dengan men sentrifus sampel untuk mempercepat dan mempermudah pengambilan larutan super natant sampel. Air kunyit $0,125 \%$ bertujuan untuk membantu membentuk kompleks warna rosa (kelat rosasianin) dan reaksi/molekul komplek yang terbentuk sehingga sehingga dapat menyerap sinar pada daerah UV (Silalahi. Dkk 2010; Triastuti dkk. 2013. Nurkholidah \& Jose, 2012). Larutan asam sulfat pekat dan asam asetat glasial berfungsi mempermudah menguraikan boraks menjadi asam borat (Kresnadipayana \& Dwi, 2017). Larutan etanol befungsi melarutkan kurkumin secara sempurna.

\section{KESIMPULAN}

Berdasarkan hasil penelitian diketahui bahwa terdapat 1 sampel dengan kode Ft3 yang terdeteksi mengandung boraks. Kadar boraks dalam sampel Ft3 sebesar $0,058 \%$.

Untuk penelitian selanjutnya dapat meneliti kandungan boraks pada Lontong, Cilok, Kerupuk Mentah dan Tahu yang ada di pasar Kota Jambi dengan 
Spektrofotometer UV-Vis pada semua sampel yang digunakan. Sebaiknya pada masyarakat sekitar lebih berhati-hati dalam mengkonsumsi bakso, lebih baik menanyakan terlebih dahulu kandungan dari bakso tersebut.

\section{DAFTAR PUSTAKA}

Binus University. (2016). Boraks Pada Pangan. Jakarta: Binus University.

Fitri, M. A., Rahkadima, Y. T., Dhaniswara, T. K., A'yuni, Q. \& Febriati, A. (2018). Identifikasi Makanan yang Mengandung Boraks dengan Menggunakan Kunyit di Desa Bulusidokare Kecamatan Sidoarjo Kabupaten Sidoarjo. Jurnal of Science and Social Development; 1; 9-15.

Hartati, F. K. (2017). Analisis Boraks Secara Cepat, Mudah Dan Murah Pada Kerupuk. Jurnal Teknologi Proses Dan Inovasi Industri; 2; 33-37.

Kresnadipaya, D. \& Dwi, L. (2017). Penentuan Kadar Boraks pada Kurma dengan Metode Spektrofotometri UV-Vis. Jurnal Wiayata; 4; 23 30.

Nurkholidah, I., M., \& Jose, C. (2012). Analisis Kandungan Boraks pada Jajanan Bakso Tusuk di Sekolah Dasar di Kecamatan Bangkinang Kabupaten Kampar. Jurnal Ilmu Lingkungan; 6;
134-145.

Pane, I. S, Nuraini, D. \& Cahaya, I. (2012). Analisis Kandungan Boraks $\left(\mathrm{Na}_{2} \mathrm{~B}_{4} \mathrm{O}_{7.10} \mathrm{H}_{2} \mathrm{O}\right)$ Pada Roti Tawar yang Bermerek dan Tidak Bermerek yang Dijual di Kelurahan Padang Bulan Kota Medan Tahun 2012. Pharmacon; 2; 1-2.

Sayuthi, M. I. \& Puji, K. (2017). Validasi Metode Analisis Dan Penetapan Kadar Paracetamol Dalam Sedian Tablet Secara Spektrofotometri uvvisible. Prosiding; Seminar Nasional Kimia FMIPA Unesa.

Silalahi, J., Meliala, I. \& Panjaitan, L. (2010). Pemeriksaan Boraks di dalam Bakso di Medan. Majalah Kedokteran Indonesia; 60; 521-525.

Suseno, D. (2019). Analisis Kualitatif dan Kuantitatif Kandungan Boraks pada Bakso Menggunakan Kertas Turmerik, FT-IR Spektrometer dan Spektrofotometer Uv -Vis. Indonesian Journal of Halal; 2; 1-9.

Triastuti, E., Fatimawali \& Revolta, M. (2013). Analisis Boraks pada Tahu yang Diproduksi di Kota Manado. Jurnal Ilmiah Farmasi; 2; 69-74.

Widelia, P., Farizall, J. \& Narti, M. (2018). Identifikasi Kandungan Boraks pada Mie Basah di Pasar Tradisional Kota Bengkulu. Jurnal of Nursing and Public Health; 6; 58-62. 